DOI: https://doi.org/10.47405/mjssh.v6i9.990

\begin{tabular}{|c|c|}
\hline 4.581 & Malaysian Journal of Social Sciences and Humanities (MJSSH) \\
\hline $\begin{array}{l}\text { Malaysian Journal of } \\
\text { Social cciences and }\end{array}$ & Volume 6, Issue 9, September 2021 \\
\hline (MJ-SSH) & e-ISSN : 2504-8562 \\
\hline & $\begin{array}{l}\text { Journal home page: } \\
\text { www.msocialsciences.com }\end{array}$ \\
\hline
\end{tabular}

\title{
Parental Attitude and Parental Intervention Strategies on Digital Media Usage Among Young Children
}

\author{
Ka Vian, T. ${ }^{1}$, Zhooriyati, S. M. ${ }^{1}$ \\ 1Department of Psychology, Faculty of Social Sciences and Liberal Arts, \\ UCSI University Kuala Lumpur, 56000 Cheras, Kuala Lumpur Malaysia \\ Correspondence: Ka Vian, T. (avian tan@hotmail.com)
}

\begin{abstract}
Technology-focused parenting has evolved to provide a constantly updated digital experience for the new digital populations while parents mitigate the risks of digital media exposure in this modern society. This study explores parental attitude on the impact of digital media and their respective parental intervention strategies. There were five parents recruited through purposive sampling technique and they participated in in-depth interview. Parents generally hold positive attitude towards digital media. They apply different parental strategies for children's media activities and its contents. This study addressed relationships pertinent to current parental strategies, media and child's factors. Considerable possibilities and patterns to nurture young children with digital media has been elucidated through uncovering parents' perspectives and challenges.
\end{abstract}

Keywords: Media activities, media contents, parental attitude, parental intervention strategies, young children's digital media experience

\section{Introduction}

Digital devices with the features of portability, accessibility of content over the internet and screen size are soon becoming the children's favourite tool to access digital media (Kabali, Irigoyen, Nunez-Davis, Budacki, Mohanty, Leister, \& Bonner, 2015). With their specific characteristics, digital media serves multiple functions as entertainment and communication tool besides educational purpose (Clark, 2011). On top of enhancing children's digital competency and literacy, parents view that digital media provides opportunity in developments of their children's critical thinking, autonomy, self-management, and social relationship (Bartau-Rojas, Aierbe-Barandiaran, \& Oregui-González, 2018).

Digital devices have been commonly used as "digital pacifiers" to keep the child calm in public places and assist in sleeping. Children are usually made occupied with digital devices while their parents are on the busy end like doing house chores. Thus, it is not surprising that ownership of mobile devices for children has already started before age three as compared with television. However, it has contributed to family isolation as users are usually surfing internet or playing video games in different social contexts. The monitoring of children's digital devices usage has becoming more challenging due to its portable characteristic (Clark, 2011; Holloway \& Valentine, 2003; Shin \& Li, 2016).

The ideal age for children to be exposed and owning a mobile phone was still a debate among parents and educators (Ling \& Helmersen, 2000). Despite that large number of children have relatively 
developed their technology skill since young age, parents and other caregivers, undeniably, are mainly as children's monitor and facilitators on their media use (Chiong \& Shuler, 2010). William and William (2005) claimed that detraditionalization of family which involves increased negotiation and more trust between child and parent is a new direction in parenting. Technology-focused parenting has evolved in this contemporary society to provide an appropriate digital experience for the new digital populations and mitigate the negative effects that may be posed from the unstoppable revolutionization of digital communication tools.

There was nearly $32 \%$ of digital media users who were accessing digital devices with internet feature as early as five years old in Malaysia (MCMC, 2016). Besides the early exposure of internet experience, 75 percents of participants in an investigation with estimated 10 thousand middle age children and adolescents in Malaysia reported that home was chosen as the most common place for them to get internet access. Furthermore, 26 percents of participants indicated that parents as their role model or starting point in learning internet skills (International Telecommunication Union, 2013). While there are research gaps exist pertinent to the precursors and the types of parental intervention strategies on young children, it is worth to explore the technology-focused parenting in Malaysia through an in-depth research.

Undeniably that there is sky-high demand on digital devices along with rapid media landscape transformation over the past decades. The traditional method of parental intervention strategies, such as "active mediation" that involves discussion on the media content or issues faced by the children, and "restrictive mediation" that set rules with lacking of clarification may no longer be adequate as far as the knowledge gap between parent and child increases (Shin, 2015). Thus, from the figures of early exposure on digital devices with consideration of diversity in parenting, current research is interested to understand parental attitude on the impacts of digital media and the types of parental intervention strategies employed by Malaysian parents.

\section{Literature Review}

\section{Parental Intervention Strategies}

There are three popular parental intervention strategies used by parents of new generation (Clark, 2011). Firstly, "active mediation" is a strategy for parents to provide information and involve children in discussion on the media content in an effort to promote children's understanding. This type of intervention strategy could be labelled as supervision, instructive mediation and technical safety guidance followed after the invention of wide-ranging media activities. Secondly, "restrictive mediation" is broadly recognised as a top-down parent-child interaction which parents are setting firm rules with certain boundaries on the digital media usage. Technical restriction is one of the restrictive methods which parents used software or tools to block inappropriate content found on internet (Nikken \& Jansz, 2014; Livingstone \& Helsper, 2008; Valkenburg et al., 1999). Thirdly, "co-viewing" or "cousing" describes parents who present at the moment during their children's media usage. Unlike the first two intervention strategies, "co-viewing" is relatively passive which both parent and child share the same media platform but rarely communicate or discuss verbally on the media content (Valkenburg et al., 1999).

It was suggested that active mediation is more effective than other types of parental intervention when it comes to children's media usage as it encourages critical thinking among the children (Fujiko \& Austin, 2002). For instance, children will be experiencing "relational system of mutual reciprocity" when parents are giving positive responses during communication. Children tend to be more receptive as well as expressive to parents and hence increase internalization expectations from parents (Laible \& Thompson, 2007). Unlike active mediation which requires extensive time and knowledge from parents, restrictive mediation especially time restriction is favoured by parents as it can be used conveniently. It was found effective when applied to younger children. That in return it has led to higher practice of restrictive type of intervention strategies (Livingstone et al., 2011, Nathanson, 2001; Warren et al., 2002). In addition, Grusec and Davidov (2007) supported that when comparing both young and older 
children, younger children would conform more to parental authority. However, it was suggested that time restriction would cause confusion among young children while their sense of time was not fully developed (Chiong \& Shuler, 2010; Livingstone et al., 2014).

When there is yet to have conclusion on the impact of new technologies on child's development, parental strategies play a crucial role in mediating the impact of digital media towards young children (Clark, 2011).

\section{Parents Media Use and Attitude}

Parents express mixed attitudes toward media. Interestingly, it appeared that their attitude changed with the age of child, and hence predicted parental mediation strategies. For instance, parents would encourage their children's media screen time with less restriction if they think that children can be benefited in terms of emotional, cognition and physical development. Secondly, parents who viewed media as too complicated usually technically restrict their children's media use and less likely co-use and apply active mediation (Lauricella, Wartella, \& Rideout, 2015). Previous researches suggested that parents engaged less intervention could be due to overestimation of children's maturity level. Parents did not perceive a huge impact of media to their own child as compared to other children ((Davison, 1983; Hoffner \& Buchanan, 2002; Meirick, Sims, Gilchrist, \& Croucher, 2009; Livingstone \& Helsper, 2008; Nathanson, Eveland, Park, \& Paul, 2002; Robinson \& Kim, 2004; Tsfari, Ribak, \& Cohen, 2005).

Child's age and skills in navigating digital devices, parent attitudes on the impact of digital media and their own screen time could be a determinant of young children's screen time. For instance, media coviewing between parents and children could be predicted by them engaging in common activities. Hence, it indicated children's mobile devices usage or online behaviour is easily monitored by parents (Connell, Lauricella, \& Wartella, 2015). On top of that, parents who are frequent media users themselves seldom participate in discussion on their children's media use and they tend to be less restrictive. (Nikken \& Schols, 2015). Even then, they would be discussing on specific concerns such as exposure to child-inappropriate content or it was when the child raised questions related to media content. Nevertheless, parent's perception and their behaviour seem contradicted as they were using different strategies even though they know that communication is crucial to promote safer online environment for children (Shin, 2015).

It is unclear to explain how and why parents choose to use certain intervention strategies based on different communication technologies. Both children and parents experience different perception and emotions on media content. For instance, children enjoy the presentation of the media. Contrarily, parents feel concerned about the effect of media content. To balance the constantly change in everyone's needs with economic environment, parents especially mother tend to take up the role to negotiate and guidance of technology usage that are related to family dynamic (Livingstone, 2009).

\section{Methodology}

A qualitative method using narrative research design was conducted in Klang Valley area on five parents who were chosen based on purposive sampling technique. Participants who met all the criteria participated in an in-depth interview. The criteria of participants are (a) both parent and child access to any digital media every day, (b) their child must be aged between 2 to 6 years old as this is a critical stage where children are actively exploring their environment with their rapidly developing physical, intellectual and social skills. The interview questions were designed using the research questions and validated with subject matter experts. The audio recorder was used to record the interview with parents with their consent. The collected data was transcribed and analysed using Thematic Analysis.

The process of this research begins with providing the consent form. The form was attached together with an information sheet and distributed to parents through preschool after getting the approval. The information sheet consists of the purpose and description of the current study, criteria of participant, 
duration, and potential risk induced from the research process. Full consent was obtained from the parents prior to the study. Parents who agree to participate in this research was contacted to fix an appointment for the interview. Reformulation of stories presented by participants were applied to find the patterns, relationships and common themes. Specifically, techniques like identifying (a) repetition e.g. the frequency of the same concept mentioned by participants; (b) similarities and differences e.g. comparison of the transcript presented by same and different participants; and (c) linguistic connectors e.g. words or phrases like "because", "before", and "is a" that indicates relationships were used. Ultimately, both explicit and implicit ideas expressed by parents were organized and put into words after discovering the themes.

\section{Result}

Total five Chinese female between 29-40 years old has participated in this research. The family size of participants ranged from 4-6 members, which two participants stay with nuclear family and another three participants have both biological parents and children in a household. Among five participants, four participants have two children and one participant has one child. A total of nine children's age ranged from two to six years old were studied in current research. The data obtained has created into several codes and theme. The discussion below has divided into two research questions to discuss the results.

\section{Parent's Attitude on Digital Media and its Impact on Young Children}

\section{Early exposure to digital devices}

Most participants reflected that they did not deliberately make decision whether they should or should not expose their children to screen time at early age. However, providing entertainment is the first and foremost factor that lead to early access of digital devices. It is followed by educational purpose and convenience in navigating the devices. Besides, it is also acts as a platform for children to socialize with peers through different media channels.

For parents, digital media fulfills the children's demand of attention from parents while parents were busy with personal work and house chore. The introduction of long-play music player has contributed to children's exposure of digital media as early as new born stage while it provides soothing purpose. Eventually, the parental readiness to introduce screen time for their children has becoming earlier based on the rewarding experience starting from infant age. Thus, it is not surprising that young children's exposure to screen time are acceptable at the age of less than 12 months old. Nonetheless, most children started exposure to screen time at age in between 18-36 months old.

\section{Positive attitude on digital media}

The exploration of children and parents' digital media experience in family constituted as a general objective in current study. First discovery about parents' attitude on digital media and rationale behind their intervention strategies revealed that parents were optimistic on media effect towards their children's development. In their opinions, digital media makes convenient delivery of message and information, photography features and apps that capture the beautiful moments of family, and great chance to bond with their children through games and movies with less hassle. Besides heightened parent-child bonding opportunities, parents show gratefulness on the educational value from the presence of digital media. As one participant pointed:

"Education book and IQ game app helps to motivate my kids in wanting to know more about the story...I usually let my daughter to play educational app that can track her learning progress." 


\section{Negative attitude on digital media}

Regardless of how parents praise the benefits that digital technologies brought to their family especially in diversifying educational experiences, some parents have drawbacks from the impact of digital media. Without proper supervision from parents, children's psychosocial development would potentially be negatively affected if they have no limit with usage duration or accidentally exposed to child-inappropriate contents. The types of advertisement that pops up half way of screening and during game playing was the major concern of participants. Besides that, participants faced difficulty when they encountered their children's request from watching the trendy unboxing toys from YouTube channel. The concept about money value has been deviated and that resulted in materialism among young children. As recalled by one participant:

"Previously, my daughter was very addicted to the surprise eggs that she
demanded me to buy for her, she also got a lot of them as her birthday present
from her aunties. Some toys are very small that it's meaningless and mostly
are very expensive. I don't know why my daughter like it so much, maybe she
likes the feeling of opening the surprise eggs, but she only played them a while
and put them aside... You know the amount of the eggs that she had is huge
that I can donate them for Easter Day! Luckily, it's just a trend, she is no
longer playing with them but it had caused me a lot of money to buy for her."

Apart from the influence from digital media, sedentary habit while using digital devices together with the "Autoplay next video" feature in YouTube channel had contributed to their young children's unresponsiveness, physical and mental health issue. They noticed that their young children sometimes tend to watch passively that may impact their creative thinking. They were also concern it might intensify to social barrier among the children when they are out of digital context.

\section{Digital media as "digital pacifier"}

Most of the participants usually made effort to encourage their children to participate in fun learning activities regardless of parents' busy schedule. Half of the participants did not indulge their children with high frequency usage of digital devices. That having been said, using the digital media as "digital pacifier" seems like effortless parenting to keep the child from demanding further from parents in some circumstances. Children would be made occupied with television program, video games and entertainment video from tablet or phone. One participant recollected her memory from her children's habit two years ago:

"I will let my kids to watch iPad with time limit like 30 to 60 mins, I will also verbally remind them about the time. I didn't set the restricted mode on YouTube but I will come to check when passing by...sometimes their screen time was extended as I was really busy with my work that I forgot to stop them. Sometimes they can watch until 2 hours without me noticing."

On top of that, majority of the parents allow the use of digital devices when they are outside of home especially travelling in car, during meal time, and family gathering. As parent reported:

"Sometimes my daughter will eat home cook food before we go out for a meal. So, you can imagine that she may get boring when she waits for us to finish ours. We would ask daughter if she wants to watch iPad, sometimes she says yes but sometimes she doesn't. So we still have to prepare the drawing tools for her to pass time. We don't really have fix routine or rule, sometimes when she finished her food earlier then she will ask for the iPad so we will give it to her." 
DOI: https://doi.org/10.47405/mjssh.v6i9.990

\title{
Parental Intervention Strategies on Media Activities
}

\section{Time Restriction}

In regard with second research aim, the result revealed that parents use different parental intervention strategies depending on the types of media activities. In common, parents use restrictive mediation such as time restriction for entertainment content. Children were usually driven by nursery rhymes video, human-like and gender-specific film, and video games. Most participants seldom co-viewing and gave explanation to their children with the assumption that digital media is a good option to kill time while providing children a gateway to relax. With its convenience and effortless practice, time restriction was selected as the most frequently used parental intervention strategy for young children.

Some parents felt that they tend to lost track on child's media activities and have difficulty to join their children in this individualized media activity. Hence, participants in this study tried to set certain time frame of the day and the duration of accessing digital media or grant the usage on weekend only. However, the reason being that time restriction is not always effective in most families because young children were becoming more expert in negotiation skill to seek for time extension approval. It was reported that most common scenario between child and parent is as shown below:

\section{Child: "But I still want to watch, I can't sleep without watching... and I don't want to sleep now!" \\ Parent: "Okay, I'll give you another five minutes and you will need to keep that away when I come back."}

Some children would accept parents' explanation and implementation of firm time restriction. However, some children struggle to follow and that has led to crying and outburst to manipulate their parents' command. In return, there were mix responses from parents in different instances and settings. In occurrence when child throw tantrum at home, parents would mostly not be tolerating their child's noncompliant. On the other hand, some parents would grant more screen time for their child when they are in public area.

\section{Content Restriction and Direct Limitation in Accessing Digital Devices}

Content restriction and direct limit access were used as a general method in managing children's screen activities such as preventing children from exposing to child-inappropriate contents. Another reason behind of this intervention strategy was to increase the quality of bonding time instead of individually preoccupied with extensive screen time.

"People and Blogs" category in YouTube channel has received the most debate from participants. Some participants noted as their children were watching video on craft making and science experiment, it served as a platform of both entertainment and educational. Nevertheless, some participants gave feedback on the hidden risk from the videos. In such case, direct restriction was used as recalled by parent:

\begin{abstract}
"You know there is a trendy video series that has characters dress up in Spiderman and Elsa, I don't allow my son to watch as I think it shows violence and sometimes sexual and disturbing content. To my surprise, it will still pop up as suggestions in the app even though I have put restricted mode. No matter what, I told my sons to avoid watching those videos in case it pops up again."
\end{abstract}

\section{Active Mediation: Explaining and Discussing to Promote Understanding}

Participants usually allow more degree of freedom on their children's digital game activities. Nevertheless, participants would be more alert and actively involved in discussion with their children on the features and potential negative effect if they were accidentally exposed to child-inappropriate 
video contents and games. Instead of using restriction, active mediation that constitute of discussion was more common for those young children who were presumed as easy temperament and more mature by parents. On top of that, the types of intervention strategies were affected by the types of media activities too. For instance, participants would typically provide guidance while their children were accessing educational media programs like educational videos in YouTube and reading apps.

\title{
Integration of Different Parental Intervention Strategies
}

For some participants, cooperation from family members and consistency of parental intervention strategies are essential in establishing a suitable digital media experience for the children. Parents viewed that an appropriate routine and discipline would help to gain conformity from their young children. But practically, participants were not entirely rigid in their parental intervention strategies on children's digital media use. There are a number of considerations for intervention strategies applied by participants such as settings, children's personality and maturity level, parents' readiness and media activities. As reported by one participant:

\begin{abstract}
"One thing is my daughter is understanding and knows how to control and won't excessively use the devices. If in that case, then we have to stop her especially before she sleeps. I explain to her why cannot watch iPad too much since young as her eyes will spoil and have to wear glasses. So, she got scared and she remember it forever... We never really set up a routine, we just let it be since she is not addicted to it so we don't really have to worry much."
\end{abstract}

The emphasis of individualism in mobile phone and tablet usage had reduced parent-child interaction while accessing digital media. Still, participants took on the role of supervision without active involvement. Besides that, young children being exposed to child-inappropriate contents e.g. violent and sexual is considered as most unfavourable incident when they access digital media. Thus, participants would choose to be in control of child's access to media contents while co-using or they might apply verbal explanation and technical restriction. Nonetheless, there were two participants encouraged more experiential learning which they did not filter the channels using restricted mode. They prefer to supervise and involve children in discussion on the media contents. It was noted that participants integrated different parental intervention strategies like co-viewing, supervising, discussion and commonly used restrictive mediation to mitigate negative effect as well as to enhance positive effect of media contents. Like one participant shared:

\begin{abstract}
"I usually let them watch iPad for about 30 minutes before they shower every day right after they come back from school. I may co-view for a few minutes if the contents interest me, then I will monitor them from distance while I am busy with house chores. I will step in and question my sons when I hear that they are watching the video that is not suitable for them. I will check the system again why those videos still exist even after I put restricted mode."
\end{abstract}

All in all, participants in current study were aware of the limitation of each parental intervention strategies as it depends on every single child in different situations. Most participants seldom use active mediation that encourage discussion on the media contents. Nevertheless, some participants would try to satisfy children's inquisitiveness by updating themselves with children's digital learning features aside from general knowledge. Despite time restriction was assumed as ineffective intervention strategy in current study, it was the most popular intervention strategy used as it was convenient in implementation.

Lastly, participants generally put effort to create a home environment with little or without distraction from screen time. Other than parental role, there is one participant acknowledged the proactive role of school teachers in promoting healthy digital media use and prevention of cyberbullying. She viewed that parents and school teachers should maintain a good teamwork where they educate and monitor closely on children's digital media use. Should there be any chance when children being exposed to 
negative influence from peers or other parties when they get older, critical thinking would come into role to make judgement on the purpose and effect of using digital media.

\section{Discussion}

In extension of research on parental attitude towards digital media, current study found that parents had positive view on digital media as it served as multifunction purposes like education, entertainment and family bonding. Bartau-Rojas, Aierbe-Barandiaran, and Oregui-González (2018) in their study reported that parents viewed the digital media negatively especially those with internet function. This result discrepancy could be explained by different age groups of children studied in both researches. It was proposed that older children were more likely to have power struggle with parents due to restriction in accessing digital media. Current study targeted on young children aged two to six years old who have yet to acquire full autonomy from parents. Thus, the concern of parents in current study was relatively lower than parents who have older children.

Parents with young children, generally expressed more positive remarks on digital media especially when children access to age-appropriate media activities and media contents. Though, parents did complain on the potential risk exposed to children's physical and psychosocial developments. It seems that parental attitude on digital media played its part in family dynamics by determining the children's exposure to digital media and parental intervention strategies applied in contemporary families (Nikken \& Jansz, 2006; Nikken \& Schols, 2015; Shin \& Li, 2016). Another parental factor suggested by Nikken and Schols (2015) was that parents' own screen time contributed to the types of parental intervention strategies. The more time parents spent in media usage, the lesser the active and restrictive mediation would they apply on their children. In the contrary, this can be explained that parents who appeared to be high media user themselves were conscious of the impact of digital media towards their children. Through granting more autonomy to young children as well as active discussion across varieties of media activities, there was noted improvement in children's learning experiences. It was possible that parents in current study were more assertive to invite children for open-discussion because of the handy source of information that parents could access through online.

Besides, restrictive mediation is the most frequently and consistently applied parental intervention strategy. It acted as a preventive measure that address the issue of children's misbehaviour at any time or it did show its effectiveness in some cases. Despite that, there were challenges in executing time restriction strategy regardless of its convenience in implementation because young children's time perception has yet developed. This assumption has been supported by two other researches respectively in Livingstone et al. (2014) as well as Chiong and Shuler (2010). More significantly, children would often try to bargain with parents for the purpose of extending time of media usage. This phenomenon also resonated the statement of "detraditionalization of family" that constituted of increased trust and negotiation between parent and child (William \& William, 2005). Henceforth, it could lead to unsuccessfulness in executing time restriction on children nowadays.

Interestingly, content restriction received absolute compliance from young children. For instance, they obey when they were asked to stop accessing those inappropriate media contents in the situation when they were unintentionally exposed to it. It could possibly be parents have already explained and warned their children against the detrimental effects of those media contents. Reasonably young children would show respect to parents' authority. They are still dependent and spend most of the time with parents. Hence, parents tend to receive more conformity from their young children (Shin, 2015). As mentioned above, parents' main initiative to start conversation with their children during the media usage was in the condition when children are exposed to inappropriate contents. This parent-child interaction was supported by study in Shin (2015) who found that top-down communication without proper explanation was the popular practice among parents. For example, "skip if you see this" and "which channel cannot watch" were among the regular commands from parents as a more direct and quick solution approach rather than providing explanation to young children. 
Other than restrictive strategy, parents applied active mediation strategy regardless of their children's actual age as long as their children were perceived as cognitively and emotionally mature to process the information during the conversation. It was suggested that while children started gaining independence, the effectiveness of active mediation was promising as the comprehension level and openness towards parental expectation increased when they get older (Laible \& Thomson, 2007). Parental perception of children's increased competency on digital media that lead to mutual communication between parent and child was indeed a great effort made by these parents. Parents were motivated and enjoyed the continuity of conversation with children while there was relatively small knowledge gap between parent and young children.

Nonetheless, it was noted that there were possibilities of widen in gap between parent and child when they were growing to adolescent age (Shin, 2015). Children will be attracted by unlimited and varieties of up-to-date digitized contents while they have increased desire to be connected with peers who share similar interests. Thus, the high availability of trendy gaming apps that feature virtual world provide an ideal media platform that fulfil their needs of socializing and mastering their personal control. Parents would start to feel conflicted which on one hand, they wished their children were able to extend their autonomy through exploring the real and digital world within reasonable limits but on the other hand, they face the challenges to communicate with their growing up children. It relates to current result which supported the claim by Connell, Lauricella, and Wartella (2015) that parents seldom co-use the media with their children with assumption that parents respect individualized characteristics of media usage. However, both parent and child would co-use when they share similar interests. This phenomenon has also proved that the interest and online activities seems to be varied between parent and child.

\section{Implication}

In general, parents incorporated different approaches for children's media activities especially it was for educational purpose. For instance, active mediation strategy was common but there were times when parents entrust the educational value of media without active involvement. As such, the flexibility in technology-focused parenting has earned its own merit with an appropriate management in the degree of flexibility. Likewise, home environment and children's factors like receptive readiness and personality were the factors to consider during implementation of the most suitable parenting for young children. Furthermore, the supportive role of family members and school authority in providing practical media usage guidance would extensively ease parents from difficult conditions during the intervention to young children.

This research has offered information pertinent to the antecedents of parental intervention strategies that future researchers could further investigate on. Furthermore, valuable information on the relationships between effectiveness of strategies, media factors as well as parents and children's factors were also provided to educators and policy makers. By understanding parents' concerns and their challenges, educational program and specific technology-focused parenting technique could be developed. Since result showed that parent and child seldom co-use because of different interest on media contents. Thus, the chance of bringing them close together with the presence of digital media is likely to increase if there are more Apps invention that consider the mutual interest of both parents and children.

\section{Conclusion}

In conclusion, the research on parental intervention strategies was complicated by taking into account of the richness of relationship among research variables. Likewise, huge research possibilities in parental intervention strategies were generated for future researchers. Last but not least, there was likely increased in awareness among parents and educators with the publish of this research. Ultimately, should there be accessible general and personalised guidelines to promote a meaningful digital experience that can benefit all families. 


\section{References}

Bartau Rojas, I., Aierbe Barandiaran, A., \& Oregui González, E. (2018). Parental mediation of the internet use of primary students: beliefs, strategies and difficulties. Comunicar: Media Education Research Journal, 54(26), 71-79. doi: 10.3916/C54-2018-07

Chiong, C., \& Shuler, C. (2010). Learning: Is there an app for that. Investigations of young children's usage and learning with mobile devices and apps. New York: The Joan Ganz Cooney Center at Sesame Workshop.

Clark, L. S. (2011). Parental mediation theory for the digital age. Communication Theory, 21(4), 323343.

Connell, S. L., Lauricella, A. R., \& Wartella, E. (2015). Parental co-use of media technology with their young children in the USA. Journal of Children and Media, 9(1), 5-21.

Fujiko, Y., \& Austin, E. W. (2002). The relationship of family communication patterns to parental mediation styles. Communication Research, 29, 642-665. doi:10.1177/009365002237830

Grusec, J. E., \& Davidov, M. (2007). Socialization in the family: The roles of parents. In J. E. Grusec \& P. D. Hastings (Eds.), Handbook of socialization: Theory and research (pp. 284-308). Guilford Press.

Holloway, S. L., \& Valentine, G. (2003). Cyberkids: Children in the information age. London: RoutledgeFalmer.

International Telecommunication Union. (2013). Measuring the information society. Retrieved from https://www.itu.int/en/ITUD/Statistics/Documents/publications/mis2013/MIS2013_without_An nex_4.pdf

Kabali, H. K., Irigoyen, M. M., Nunez-Davis, R., Budacki, J. G., Mohanty, S. H., Leister, K. P., \& Bonner, R. L. (2015). Exposure and use of mobile media devices by young children. Pediatrics, 136(6), 1044-1050.

Laible, D., Thompson, R. A., \& Froimson, J. (2007). Early socialization: The influence of close relationships. In J. E. Grusec \& P. D. Hastings (Eds.), Handbook of socialization: Theory and research (pp. 35-59). Guilford Press.

Ling, R., \& Helmersen, P. (2000, January). "It must be necessary, it has to cover a need": the adoption of mobile telephony among pre-adolescents and adolescents. Paper presented at the conference on the social consequences of mobile telephone. Retrieved from

https://www.researchgate.net/profile/Rich_Ling/publication/259257260_It_Must_Be_Necessary_It_H as_to_Cover_a_Need_The_Adoption_of_Mobile_Telephony_Among_Pre-

Adolescents_and_Adolescents/links/560773c108aeb5718ff7d38c/It-Must-Be-Necessary-It-Hasto-Cover-a-Need-The-Adoption-of-Mobile-Telephony-Among-Pre-Adolescents-and-

Adolescents.pdf

Livingstone, S., Haddon, L., Gorzig, A., \& Olafsson, K. (2011). Risks and safety on the internet: the perspective of European children: full findings and policy implications from the EU Kids Online survey of 9-16 year olds and their parents in 25 countries. Retrieved from http://eprints.1se.ac.uk/33731/1/Risks\%20and\%20safety\%20on\%20the\%20internet(1sero).pdf

Livingstone, S., \& Helsper, E. J. (2008). Parental mediation of children's internet use. Journal of Broadcasting and Electronic Media, 52(4), 581-599.

Livingstone, S., Marsh, J., Plowman, L., Ottovordemgentschenfelde, S., \& Fletcher-Watson, B. (2014). Young children (0-8) and digital technology: a qualitative exploratory study-national report-UK.

Retrieved

from http://eprints.1se.ac.uk/60799/1/_lse.ac.uk_storage_LIBRARY_Secondary_libfile_shared_repo sitory_Content_Livingstone, $\% 20$ S_Young $\% 20$ children\%200-

8_Livingstone_Young\%20children\%200-8_2015.pdf

Malaysian Communications and Multimedia Commission (2016). Internet users survey 2016. Retrieved from https://www.mcmc.gov.my/skmmgovmy/media/General/pdf/IUS2016.pdf

Nikken, P., \& Jansz, J. (2006). Parental mediation of children's videogame playing: a comparison of the reports by parents and children. Learning Media and Technology, 31, 181-202. doi: $10.1080 / 17439880600756803$.

Nikken, P., \& Jansz, J. (2014). Developing scales to measure parental mediation of young children's internet use. Learning, Media and Technology, 39(2), 250-266. 
DOI: https://doi.org/10.47405/mjssh.v6i9.990

Nikken, P., \& Schols, M. (2015). How and why parents guide the media use of young

children. Journal of Child and Family Studies, 24(11), 3423-3435.

Shin, W. (2015). Parental socialization of children's internet use: a qualitative approach. New Media \& Society, 17(5), 649-665.

Shin, W., \& Li, B. (2017). Parental mediation of children's digital technology use in Singapore. Journal of Children and Media, 11(1), 1-19.

Valkenburg, P. M., Krcmar, M., Peeters, A. L., \& Marseille, N. M. (1999). Developing a scale to assess three styles of television mediation: instructive mediation, restrictive mediation, and social coviewing. Journal of Broadcasting and Electronic Media, 43(1), 52-67.

Warren, R., Gerke, P., \& Kelly, M. A. (2002). Is there enough time on the clock? Parental involvement and mediation of children's television viewing. Journal of Broadcasting \& Electronic Media, 46, 87-111. doi: 10.1207/s15506878jobem4601_6

Williams, S., \& Williams, L. (2005). Space invaders: the negotiation of teenage boundaries through the mobile phone. The Sociological Review, 53, 314-331. 